\title{
The crisis of transition and the transition of crisis
}

\begin{abstract}
There is no doubt that transition and crisis are functionally linked and interdependent. Crises are permanent and, according to previous experience, inevitable companions of the capitalist mode of production. Events in the last decades of the twentieth century provide the basis for a conclusion that transition was caused by the crisis of the system but also that transition, in its essence, can be viewed as a special case of crisis. Transition is a process which is fundamentally associated with the countries of central and eastern Europe. However, it would be wrong to conclude from this that it is a process of regional character. On the contrary, it is by nature a global one and a result of the high degree of economic and political connection and interdependence in the modern world. The transition process has been associated with economic and political processes because it has influenced these processes just as the situation of and relations in the world in general have influenced the transition process.
\end{abstract}

Keywords: crisis, transition, globalisation, political and social reforms, ethics, market economy, capitalism, freedom and human rights

\section{Introduction}

The title appears to be a play on words. Ultimately, it is one when viewed from the standpoint of linguistics and the attempt to make the spoken and the written word more beautiful and more attractive. However, it was not the intention of the authors. The title was created in the quest for an answer to the questions of the nature and character of the connection and interdependence between two phenomena which have indisputably marked the modern era - namely, crisis and transition. ${ }^{1}$ Certainly the choice of title was influenced by crisis being the most used word in Serbian in the past twenty years; a word most often used by politicians, researchers, analysts and ordinary citizens alike to describe the situation in which they have lived for almost two decades.

Crisis has been described as both cause and effect; as a permanent image of the conditions in the society in which we live; as an opportunity and encouragement for people to set up a life path for themselves and follow progress; as the 'usual suspect' for the degrading situation in which most Serbian citizens live; as an object of political and ideological manipulation; as a key battlefield for the futile election struggles through which Serbia has been passing; as the reason for fear and hopelessness; and as a spark for the mutual accusations of the different, divided political parties. It has been talked about in terms of a crisis of the economic system; a political crisis; a crisis of

1 Hase, R, H. Schneider and K. Weigelt (2005) Lexicon of the Social Market Economy Belgrade: Konrad-Adenauer-Stiftung. 
political will and of the responsibility of the political and social elite; a crisis of identity; a crisis of strategy; and a crisis of the individual - which is often manifested as a crisis of hope.

If a doctor listed as many centres and forms of crisis in the human body, they would inevitably lead to a fatal outcome. In our case, we can see the tragic images of the crisis more often through acts of self-destruction - suicides, hunger strikes and the self-injury of those who have been left without jobs, without food and without any hope of dignity and freedom. The situation in Serbia provides the basis for asking a really cynical question - if the transition is so expensive, was it worth beginning it at all? The answer is well known - transition was inevitable. But why is it so unbearably expensive?

There is no doubt that transition and crisis are functionally linked and interdependent. Following the historical course of the emergence and development of these two phenomena, it can easily be observed that crises occur earlier in time. They are the permanent and, according to previous experience, inevitable companions of a capitalist mode of production; they occur in cycles, often creating havoc in national economies as well as in human destinies. It can be said that normal life takes place between cyclical economic crises.

Transition is a new phenomenon in time, tied to the last decades of the twentieth century. It commonly denotes a process of the economic, political, social, cultural and general social changes which have been conducted over the last two decades in central and eastern Europe - i.e. in the countries of the former socialist bloc. It has unfolded with different dynamics, in different social circumstances and with varying success, but transition has essentially had the following primary course - from a one-party system of a state-controlled economy to a multi-party parliamentary democracy, private property and the market economy. The road has mostly been bumpy, with many conflicts, and has on the whole had a high social cost. It has also been shown that achieving the objectives of transition does not automatically lead to progress, i.e. the improvement of the standards, quality and dignity of human life and work. ${ }^{2}$

The historical course of events in the last decades of the twentieth century provides the basis for a conclusion that transition was caused by a crisis of the system - but also that transition, in its essence, can be viewed as a special case of crisis. It was obvious that the political and social systems of the countries of central and eastern Europe had exhausted their internal driving forces. However, the flow of the transition itself, i.e. the economic, political and social reforms which it includes, also has the character of crisis.

Transition is a process which is fundamentally associated with the countries of central and eastern Europe. However, it would be wrong to conclude from this that it is a process of regional character. On the contrary, it is by its nature a global process and a result of the high degree of economic and political connection and interdependence in the modern world. The process of transition, according to the principle of connected vessels, has been associated with economic and political processes in the world at large, because it has influenced these processes, just as the situation and re-

2 Transition and Institutions (2002) Proceedings of the symposium of the same name, Institute of Social Sciences: Belgrade. 
lations in the world in general have influenced the transition process both in some countries as well as in general. The transition process is also the result and reflection of the balance of power and the conflicts between different interests and visions in the modern world.

Finally, during the transition process in central and eastern Europe, other parts of the world have not been standing still. In other countries and regions of the world, there have also been some changes, so it can be said that the world is, as a whole, in a process of transition (although in central and eastern European countries, it has specific contents and a particular flow). When viewed in that way, the world in which we live can be defined as a train whose coaches are moving at different speeds, i.e. are in different stations of time from the standpoint of their economic and technological development. In other words, transition as a manifestation of the crisis has opened a whole new set of issues, or aspects of the crisis, which modern civil society is facing.

\section{Transition and the global crisis}

If the world in which we live is involved in the dynamic processes of movement and change, and if these trends are defined as the transition process, then the transition process of central and eastern European countries, which symbolically and actually started with the demolition of the Berlin Wall, can be seen as a special case of globalisation. In this case, a question inevitably arises - what is the relationship between the transition process in central and eastern Europe and the processes that took place in other regions of the world, indeed on a global level, during the same period? In fact, the growing number and increasing dynamics of global events represents a basic feature of the modern age which significantly influences all other social, economic and political developments. To what extent have global trends affected the progress in and results of the transition in central and eastern Europe, part of which is Serbia, and vice versa - have the experience flow and the effects of the transition in these countries influenced development and relations on the global level? Are there any common denominators, i.e. what are the differences between transition and the social processes that have been taking place in other parts of the world in the last two decades? Have the processes that took place in central and eastern European countries brought about the emergence of the current global economic crisis and, if so, to what extent? ${ }^{3}$

Transition is, by definition, the process of movement from one point to another, from one social state to another, from a set starting point towards certain social goals. In this respect, the transition in central and eastern European countries has essentially been a process of movement from the planned, controlled economy, based on state ownership of the means of production and the rule of one party - the Communist Party - to a market economy based on private property, a multi-party parliamentary democracy and a complex of human freedoms and rights. Preference was, as a rule, given to the neo-liberal concept of political and economic order. What is more, at the beginning of the transition process, the concept of so-called 'shock therapy' was imposed, which its authors and most ardent advocates quickly conceded when faced with the concept's dire economic, moral and social consequences. Nevertheless, the facts show that many

3 Vidojević, Z (2005) Where does globalisation lead? Filip Visnjic: Belgrade. 
countries in central and eastern Europe have not yet managed to recover and escape the vicious circle of transition shock.

A functional relationship between transition and globalisation was established, among other things, in such a way that the countries in transition saw as their role model the economically and technologically developed, democratic countries primarily from the European Union. In this sense, countries in transition have studied and used the experience of these developed countries, copied the models of their political, economic and social organisation, and also taken on their legislation. Even a superficial comparative analysis of the institutions and mechanisms of the political, economic and social organisation of countries in transition and the developed countries of the EU would show a high degree of similarity and even identity. However, it is also apparent that the social power of these institutions and mechanisms in these two groups of countries is nowhere near the same, i.e. the effects of their actions are visibly different. This stems from the protagonists in political and social developments in the transition countries not having adequate professional, political and other capacities to breathe real life into these institutions and give them the necessary social power, due to the influence of a whole range of constraining factors. Overcoming these differences will take a lot of time and requires an appropriate strategy for countries in transition as well as developed ones. It is certain that this difference is going significantly to influence the position of countries in transition in future global processes, as well as the very course of globalisation.

In addition, one must take into account that a model of political, social and economic organisation of society cannot be equally successful and equally accepted in different traditions, cultures and ways of life. History in general, and especially modern history, has confirmed the interdependence of a model political and economic system and the dominant cultural and ethical values and patterns in a certain location. The dynamics of integration processes in the modern world have only made this interdependence grow more, making it more visible and recognisable. The transition process in central and eastern European countries has shown that the success of this process (at least according to the criteria according to which success is customarily measured) was largely conditioned by the historical legacy, not only from contemporary history but from history in general, as well as by the dominant cultural and ethical values which characterise a certain location. In other words, every political and economic order has to be based on relevant, generally-accepted cultural, traditional and ethical values so that the order itself could also be accepted and function realistically. The transition process, in this regard, has to be seen as a conflict or confrontation between different cultural and customary patterns and the system of moral values.

This means that the transition process in central and eastern Europe cannot be viewed only in terms of its formal-legal and economic development from the state ownership of a controlled, planned economy and a one-party system to private ownership, market competition and multi-party parliamentary democracy, but the crucial determinant of this process must also be taken into account: the conflict between different cultures, lifestyles and moral value systems. This conclusion has been confirmed by the entire course of history, both in Europe and other continents and regions of the world. It can be seen from it that different models of political and economic organisation 
of society have been established in different cultures and traditions. Finally, there is also a commonly-accepted contemporary view that the capitalist, market-oriented mode of production is not just a mode of production and means of distribution of material and social wealth, but also a way of life. It follows from this that the transition process in central and eastern Europe must be viewed in the context of the overall conflict between different civilisations, cultures, traditions and ways of life which manifest themselves differently and with different intensity in the modern world. ${ }^{4}$

If we look at the transition in central and eastern Europe as a part of globalisation, then the inevitable question is - in what kind of relationship are transition and globalisation, and, above all, the current global crisis? When the transition process started two decades ago, predictions of its progress were largely optimistic and the abovementioned concept of 'shock therapy' was an integral part of these optimistic predictions. Within them, the estimates were that the transition would be completed in a relatively short period - assessed at about one decade. The facts, however, even at the beginning, but also during the entire course of this process, have shown that this optimism was unrealistic and that transition will be a much longer-lasting, more contradictory, more complex and more expensive social process in every way. Such estimates had, among other things, a strong political and ideological base - in the sense that, from the beginning, the transition process was treated to a large extent as a clash between two different types of socio-economic system and the different ideologies on which these systems were based, i.e. as a final victory of one system over another.

Numerous data and analyses conducted in recent years confirm that the transition has progressed with different intensities and different rates of success in different countries. It is still proceeding, confirming the complex and contradictory nature of the process. First of all, the course of the transition has confirmed firstly that this is not a one-way process of establishing the institutional development of economically and technologically developed democratic countries; and secondly, that it cannot in particular be equated with the process of association with the EU by certain countries. This process is much broader, more meaningful and, by its nature, must run in two directions. This is confirmed in that the transition process has taken place under the influence of the EC and its institutions but has also affected relations in the EU and Europe as a whole.

In this sense, the transition process of central and eastern European countries should be viewed within the context of the integration process in Europe in general, which began nearly six decades ago with the formation of the European Coal and Steel Community. During this process, there has been a visible tendency for strengthening and enriching the contents of integration processes, as well as a trend by the European Commission towards expansion after the demolition of the Berlin Wall. This process can be taken as a confirmation of the historical tendencies of the capitalist mode of production constantly to expand and overcome administrative and all other obstacles. In other words, the development of a capitalist mode of production includes stronger market competition, improvement of the means of production and the constant introduction of new technologies which leads to a constant increase in the amount of pro-

4 Huntington, S (2000) The Clash of Civilisations Romanov: Banja Luka. 
duced material goods i.e. an increase in the supply of goods. Therefore, it demands a bigger market. So, capitalism in its quest crosses first local, then regional, then national borders as well - and today has been established on a more global level.

If viewed from this aspect, the establishment and development of the EU up to now is by no means complete. The EU may, for tactical, political, economic and other reasons, stop or decelerate the process of its expansion for a period, but the integration process inevitably tends towards expansion. So far, the course of this process has also shown that it has an economic basis, but it is not limited only to economic aspects. This means that the question of the further perspective of EU expansion can be opened very quickly. This is not only about the countries of the so-called 'western Balkans', to which Serbia belongs. For example, there is no common sense political or economic reason that Russia should not become a member of the EU. This would certainly result in a significant change of the former concept and strategy of the EU. Europe and the world are, in this respect, now standing in front of one of the biggest challenges related to the question of essence, i.e. the human and historical meaning of the European and global integration process. This challenge confirms the organic and functional relationship of the transition in central and eastern European countries and the global crisis with which the world is faced today. At the very least, it is certain that the genie has been released from the bottle.

The world we have lived in during the past few decades is now faced with the benefits and negative aspects of its integration processes. In other words, the body of these integration processes is now impossible to be stopped. The questions are concerned only with the direction in which it will proceed and how it should be conducted so that human beings can make the best of it. ${ }^{5}$

\section{The different directions and points of contact between the transition and the global crisis}

If history is the teacher of life, then it will definitively give complete and relevant answers to the causes of the collapse of socialist systems in central and eastern Europe. What is undisputable today, and what is also apparently evident, is that these systems have indeed collapsed. This collapse was preceded by a long-lasting crisis which became more and more severe, leading to more serious and less manageable consequences. This crisis must be viewed as a part of the global crisis. The undeniability of this perspective demonstrates to us that these systems did not have sufficient internal energy or driving force to keep the system stable and capable of development in the long term. Neither did the mechanisms and institutions on which this system was based have sufficient power successfully to meet the challenges of modern times. The long-lasting and systematic slowdown in economic and technological development, i.e. the decline in the economic power of these societies, was, by general belief, caused by the limitation of basic human freedoms and rights, by the non-existence of market competition and by the lack of, or the otherwise fictitious, functioning of democratic institutions in that

5 Lairson, T and D. Skidmore (1996) International Political Economy Harcourt Brace College Publishers: San Diego. 
the one-party system was not a fertile ground for their successful operation and development.

That experience formed the belief that the introduction of such institutions would automatically mean the success of the transition. This belief was dominant in the first years of the transition, but more as ideological manipulation than an argumentative point of view. It should be added that this point of view on the causes of the crisis which led to the collapse of one-party systems in central and eastern Europe has a strong foothold in that multi-party parliamentary democracy, freedom, human rights and the market economy, which is always a match between human capabilities and knowledge, are considered indisputable achievements of modern civilisation and that the greatest achievements in economic and technological development have been reached by those countries whose social systems are based on such foundations.

If we accept that the crisis which caused the transition in central and eastern Europe emerged because of the lack of these mechanisms and institutions, then we could say that the current global crisis has operated in the reverse direction. In other words, the crisis has occurred in those countries in which the institutions of civil society - private property, the market economy and a multi-party parliamentary democracy - are most developed and which economically and technologically function at a high level. It sounds cynical, but it can be said that, in one sense, the global crisis has been caused in particular by the over-strong and consistent advance of the market economy. This has proven, for the umpteenth time in the history of civil society, that the mechanisms of the market economy include some systematic limitations which can generate a crisis. ${ }^{6}$

In this respect, we can isolate a point of contact between the transition and the global crisis. The transition of central and eastern European countries and the global economic crisis were preceded by the rise of neo-liberal ideology and an economic order in society which is based on it. In the past decades, the neo-liberal concept has dominated theoretical works and economic strategies. The dominance of this concept has been particularly pronounced in transition countries, especially in its early stages, through the adoption of appropriate legislation, so-called 'deregulation measures', free pricing, etc. The neo-liberal concept was, to a large extent, imposed by the international financial institutions - the International Monetary Fund and the World Bank - as well as by the economically and technologically most developed and powerful countries in the world. Such a concept was a condition for the financial support of the international political and financial institutions and has often been a key criterion for the evaluation of the success of economic and social reforms. The whole concept is based upon absolute trust in the power of the market as the key, or the only, regulatory instrument, as well as on a point of view and practice based on it that economic trends should be governed solely by the laws or whims of the market, on the basis that these are fair and expedient in judging which producers are able to withstand the continually harsh demands of market competition. It follows from this, of course, that the state is required to interfere as little as possible in the economic life of society.

6 Maurice, D (2003) 'Free Trade a Great Destroyer' in: Arguments Against Globalisation Clio: Belgrade. 
Consciously or unconsciously, one factor has not been considered. This first manifested itself on the local, then the national and nowadays increasingly on the global level - that, in all three levels of market competition, under the influence of sociohistorical circumstances, the protagonists of market competition have entered this state from different starting positions. This has brought into question the very purpose of competition, since this is only meaningful if it is honourable and honest, and if it is carried out under equal conditions for all participants. With the development of market competition, and the intensification of the conditions and criteria according to which it was conducted, these starting differences have increased more and more. These differences are particularly evident in the process of globalisation, which is still showing a tendency to increase. This is reflected in the well-known and unquestionable division of the world into an extremely wealthy minority and a more or less poor majority.

One of the sources of the growing gap between rich and poor lies precisely in the dominance, during the last decades of the twentieth and those at the beginning of the twenty-first century, of neo-liberalism, i.e. the imposition of a concept and practice based on uncontrolled and unlimited market activity. A conclusion can be drawn from this about the functional relationship between the permanent increase in the differences between rich and poor, which is the undisputed landmark of modern times, and the emergence and development of the global economic crisis. Economically developed countries have so far transferred the greater part of all the crises, including the current one, to the expense of poor, economically and technologically under-developed countries because it is clear that, among them, according to the principles of common sense, it was not and nor is it now possible to have equal market competition in the proper sense of the word. However, the globalisation process has a positive aspect in this regard, ${ }^{7}$ because the room for moving the economic and social cost of the crisis towards weak countries is objectively becoming smaller and smaller and will certainly, in the time before us, be reduced even further. In this respect, the contemporary world, or its economically and technologically developed and undeveloped parts, function on the principle of connected vessels.

If it is indeed true that history is the teacher of life, then the answer to these questions, which are essential for the future of the world, should be sought in an analysis of the economic crises of the capitalist, market mode of production in its historical dimension. The causes and the usual course of the cyclical crises of the capitalist market mode of production are more or less known, and are often shown and analysed in the economic, sociological and political literature. It is a peculiar fact that trade unions in particular have insisted on research into and the ending of the causes of these crises, especially within the EU. This has been confirmed in that the European Trade Union Confederation, i.e. the European Trade Union Institute as a part of the Confederation, has organised a number of projects and meetings between researchers and experts on this topic in the process of the establishment and development of the EU. This question is still at the centre of attention of the trade union struggle in Europe - which is logical since every crisis, including the current one, affects firstly and mostly the members of the working class.

7 European Trade Union Yearbook 2000 European Trade Union Institute: Brussels. 
Analysis of the causes and course of economic crises, observed chronologically, can be defined in pedagogical terms as 'revision', with the students achieving varying degrees of success in the process. Cyclical crises develop because of the substantial limitation in the functioning of the market economy. In other words, market competition - which, for the sake of truth, is becoming stronger and more demanding - is a powerful driving wheel for faster economic and technological development. The owners of capital and managers quickly realise that only the best survive on the market and that means those who are the first to introduce new, higher quality and more productive technologies. The introduction of new technologies leads to an increase in the productive, creative power of human labour which is reflected in the increasing amount of material goods produced or, in other words, in the increasing supply of goods on the market. However, new technologies have, at the same time, been mechanised, then automated and now even computerised and this means they require less human labour. Capital owners in the early stages of capitalism simply dismissed redundant employees as a result of the introduction of new technology. The workers thus formed a growing and naturally dissatisfied army of unemployed people. This diminished consumer power in society since dismissed workers are also consumers, thereby continually deepening the gap between supply and demand, and leading to the accumulation of goods in warehouses and on the market, interruption in the continuity of the reproduction process and new mass layoffs, ultimately leading to the collapse of the economic order. It seems apparent that crises in the market mode of production are caused by new, more productive technologies.

Up to now the worst crisis, both in length and in its economic and social consequences, has been the great world economic crisis in 1929, which is often called 'The Great Depression' in literature, with good reason. The tragic images of that age cause discomfort and fear even today. Closed factories, eerily empty factory halls and millions of desperate, hungry people made worthless and hopeless, wandering around and faced with the question of how to survive the day. The course of the global crisis thus far warns us with concrete facts that there exists the potential risk of repeating these tragic, humiliating scenes.

The political, economic and social picture of the world has definitely changed since the crucial year of 1929. Firstly, the concept of a classical liberal economy, based on the market as the sole regulator of economic relations and on the state as the night guard, can nowadays only be found in museums and historical readers. Confronted with the deteriorating economic, social and moral consequences of the crisis, which the previous mechanisms cannot restrain, and in a situation of social chaos and hopelessness, the state clearly enters the economic life of society and influences or directly regulates basic economic trends with the whole panoply of mechanisms. For this purpose, the state passes laws, regulations and other measures of economic policy and establishes different levels and forms of control in monetary and taxation policy - which now thus becomes an important instrument of developmental and social policy. The state develops various mechanisms of social policy and social security on the principles of social justice and solidarity. The state thus becomes the key factor in the economic life of society, which is one of the common denominators, i.e. the general characteristics of the modern era. 
Today, it is apparent that the state holds in its hands the key levers of the economic life of a society in all countries regardless of social and economic order, of the degree of economic and technological development, of the structure of the economy and population, or of culture, tradition and way of life. The question is thus whether it operates in a more or less successful way, i.e. whether it implements economic policy mainly or exclusively for the benefit of the privileged social classes, who then concentrate in their hands most of the social wealth and all the social power, or whether it works for the benefit of society in general, i.e. for the material and social welfare of all social strata. $^{8}$

By analysing the flow of the great depression in 1929, and of previous and later crises, including the current global crisis, it can easily be proven - and it is more or less indisputable - that they have the same source. Similarly, a comparative analysis provides the basis for the conclusion that states essentially use the same instruments in confronting the crises as well as their social, economic and political consequences. States take various measures individually, or often with the other protagonists of industrial relations - trade unions and employment organisations. All of these measures are ultimately aimed at the prevention, i.e. the reduction, of unemployment, which leads to a reduction in consumer power in society and to a disturbance in the balance between supply and demand. The set of these measures has been well-researched and known to a greater or lesser extent for decades. Not only in times of crisis, but also in the socalled 'peaceful times' of economic and social stability, a range of mechanisms is applied aimed at maintaining and preventing the reduction of employment. It can be said that the spectre of unemployment has been circulating in Europe for decades, occasionally getting out of control despite all the measures taken, which is confirmed by the current course of events. This causes enormous economic, social and political damage, destroying what has been created and defended for decades and bringing into question the real social power and the purpose of certain social institutions.

\section{Finding a way out - moral aspects of the crisis}

Of course, when it is said that the mechanisms of a crisis occasionally seize control and the genie is thereby let out of the bottle, this does not mean that the crisis concerned is evil fate or a natural disaster - a typhoon, a tsunami or an earthquake, which hit us occasionally and suddenly, demonstrating our inability to defend ourselves. Crises are instead images either of the efficiency of a political, economic and social strategy and/ or of an elite which has created and pursued that strategy. In other words, after the Great Depression in 1929, the efficiency of the political elite in some countries may be measured by how successfully they have opposed the causes and consequences of economic crises, which have always been, at one and the same time, both political, social and ethical. In this text, as well as in other texts on this subject, 1929 is considered crucial and not without good reason, since that crisis was the biggest and its effects the worst, but also because it definitely shattered the illusion that the market could be the only regulator in the future of economic relations within a capitalist mode of production. Of course, we inevitably ask ourselves apprehensively whether it could happen that a new

8 Chomsky, N (1999) Profit over People - Neoliberalism and Global Order Svetovi: Novi Sad. 
crisis, and perhaps even the current one, could take the place of the infamous 1929 crisis, having even more disastrous economic and social consequences.

Preventive action and direct confrontation with the crises of a capitalist, marketoriented mode of production produce different results in different periods and under different social circumstances. At the national level, these results depend on the degree of technological and economic development of a country, its economic and social structure and the strategy which is applied to deal with the crisis. However, it is obvious that the key causes of the crisis are not only still present, but occasionally re-manifest themselves with extraordinary power. Ultimately, all the measures that are used to encourage entrepreneurship, employment, social policy and more flexible forms of employment represent, in fact, only the elimination of the consequences of the systematic limitation of the market mode of production, but do not resolve the main problem. What is new, and what certainly brings in new aspects for consideration, is that this systemic problem is now moving and manifesting itself more and more on a global level, requiring the creation and implementation of appropriate measures also on a global level. The globalisation of the systematic limitation of the market mode of production may become the initial cap for its permanent solution simply because there is no more space available for the problem to expand further and move to new levels.

Crisis is, by nature, itself a kind of restriction on human freedoms and rights, i.e. the denial to workers and citizens of the previously-achieved level of human rights and freedoms and of quality of life. It should be remembered that the horizons of human liberty and dignity have been broadened over the past decades, so the concept and contents of human freedom are significantly different, richer and more meaningful than they were a few decades ago. ${ }^{9}$ In addition, the entire corpus of human rights, which includes basic human, political, economic and social rights, can only be realised as a whole. For example, the primary and indisputable right in all civilisations - the right to life - cannot nowadays be limited to the protection of human life in the physical, biological sense, meaning that no-one has the right to take a person's life, to harm them or to subject them to any form of physical abuse. The right to life today, in the new social environment, includes the right to a healthy life in freedom and dignity, which includes the entire body of other rights - such as the right to work and to have a job providing decent earnings; the right to professional and vocational education; the right to a free choice of profession and place of residence; the right to health and social security; and other rights. In other words, if any particular right from this large and rich package is called into question, it automatically brings into question the realisation of all the other rights.

This includes a re-examination of the economic and sociological concept of a subsistence minimum - on the basis of which the minimum wage and the cost of labour are determined - in terms of replacing this with the term civilisation minimum, based on the achieved level of civilisation, or with the right of every person to enjoy the achievements of modern civilisation. This is important because the consequences of the current global crisis must be observed and measured not from the standpoint of a subsistence minimum, a criterion which belongs to the nineteenth century, but accor-

9 Giddens, A (2000) The Third Way Polity Press: Cambridge. 
ding to the achievements of modern civilisation. In addition, crisis has serious consequences not only during its immediate course but, in the long run, regarding economic and human resource development, also for a strengthening and an encouraging of the destructive, conflictual aspects of social relations.

Finally, the course of the crisis itself supports the thesis that the search for the permanent elimination of its root causes has, for almost a century, been moving in a vicious circle of dealing only with the consequences. In other words, the indisputable fact, recognised at the beginning by politicians and economic experts in those countries where the crisis had begun, is that the crisis had started in the financial-banking system and in the real estate business - the birthplace of speculative capital which, as is known, can be separated very quickly and easily from the production process and its solid material basis. The bankers are formally right in saying that the crisis arose because beneficiaries had been repaying awarded property mortgage loans irregularly or had stopped repaying them completely. However, they did not just stop repaying loans because they had become indisciplined or irresponsible, or because they did not want to fulfil their obligations: they were well aware of all the consequences, including the most disastrous one - of becoming homeless. They stopped repaying the loans regularly because they had lost their job; because their salaries had been reduced; and because they had temporary, insecure jobs with no essential employment, legal or social security, causing them to live in daily fear of remaining jobless.

In this sense, the results of research studies in recent decades, both in the developed countries of the EU and the rest of the world, encompassing countries in transition, including also Serbia, ${ }^{10}$ confirm and warn that the fear of losing a job is one of the greatest fears of modern times and, according to the results of these studies, often comes ahead of the fear of death. This is conditioned by two facts - one is that this job is the only source of existence for the vast majority of employees and it is difficult or almost impossible for them to find an alternative. The other is that, by losing a permanent job in the modern way of life and social order, a worker loses a range of business, economic and social rights, leading to them actually becoming a second-class citizen.

If viewed and compared from this perspective, the process and effects of the crisis in central and eastern European transition countries and in the economically-developed capitalist countries of the EU resemble a time machine that has stopped at different stations in time. Nevertheless, we, as members of the contemporary generation, have the opportunity, or privilege, of observing essentially the same processes at their different stages and in their different time periods. This comparison also confirms that economic and technological development does not automatically create a barrier to the emergence of crisis. On the contrary, dynamic economic and technological development causes more radical forms of crisis as well as more radical economic, social and political consequences. The difference is that a society at a higher degree of economic and technological development has greater material and financial power to alleviate

10 Mihajlovic, S, Z. Stojiljkovic and G. Ivanic (2005) Trade Union Barometer Nezavisnost: Belgrade. 
and eliminate the social consequences of the crisis. ${ }^{11}$ However, the contest between the crises and the control of their social consequences to a large extent resembles a jeux sans frontières because it is clear that each fund, even the largest one, has its limits. In addition, when the level of state social intervention exceeds certain limits, it creates a whole new essence of the economic and social processes which are taking place within society.

What is also common ground for all countries in the current global crisis, both those in transition as well as the more economically and technologically developed ones, is that the social protagonists - employers and trade unions - have asked the state for help in all respects: with making new laws or changing the existing ones; adopting and implementing appropriate measures of economic, tax and social policy; getting direct financial assistance to overcome the effects of the crisis; and with intensive mediation in the growing social and industrial conflicts which have arisen as a result of the crisis. It is obvious that the state has a crucial role to play in dealing with the economic crisis and its consequences and that the key instruments for crisis management and the alleviation of its economic and social consequences lie in its hands. At the same time, as the crisis has deepened, the haughtily loud advocates of neo-liberalism in the past have become quieter, many of them being among the first to run and hide behind the mother country and its intervention. It is certain, as has been confirmed by historical experience, that the world shall look different after this economic crisis. Similarly, the role of the state during the economic crisis will permanently redefine for the future the role of the state in economic relations.

The redefinition of the whole concept of the economic, social and political order of society, as well as of the role of the state in its economic life, has lasted for decades through the introduction of social policy mechanisms; protection for the unemployed; protection of so-called 'vulnerable social groups'; development of the concept and practice of collective negotiating; employees' rights to information, consultation, codecision-making and social dialogue, which are now increasingly being integrated into strategies for sustainable development; and the concept and practice of corporate culture and socially-responsible business dealings. However, the next steps, some of which have already been made in dealing with the crisis, open the crucial question of the survival of the market-oriented, capitalist mode of production.

\section{References}

Chomsky, N (1999) Profit over People - Neoliberalism and Global Order Svetovi: Novi Sad.

Giddens, A (2000) The Third Way Polity Press: Cambridge.

Hase, R, H. Schneider and K. Weigelt (2005) Lexicon of the Social Market Economy Konrad-Adenauer-Stiftung.

Lairson, T and D. Skidmore (1996) International Political Economy Harcourt Brace College Publishers: San Diego.

11 Vuletic, V (2003) 'Globalisation - Pro et Contra' Proceedings: Globalisation Myth and Reality Zavod za udzbenike: Belgrade. 
Marx, K (1970) Das Kapital Research Institute of the Labour Movement: Belgrade.

Maurice, D (2003) Free Trade a Great Destroyer in: Arguments Against Globalisation Clio: Belgrade.

Mihajlovic, S, Z. Stojiljkovic and G. Ivanic (2005) Trade Union Barometer Nezavisnost: Belgrade

Morality and Economics (2008), Proceedings of the symposium of the same name, IDN: Belgrade.

Vidojević, Z (2005) Where does globalisation lead? Filip Visnjic: Belgrade.

Vuletic, V (2003) 'Globalisation - Pro et Contra' Proceedings: Globalisation Myth and Reality Zavod za udzbenike: Belgrade. 